\title{
A EXPERIÊNCIA ATRAVÉS DA REPETIÇÃO: A DITADURA MILITAR NO CINEMA BRASILEIRO ${ }^{1}$
}

\author{
Cristiane Freitas Gutfreind ${ }^{2}$, Helena Stigger $^{3}$ e Luiza Carmona ${ }^{4}$
}

\begin{abstract}
Resumo: O presente artigo analisa dois filmes documentários sobre a ditadura militar brasileira: Tempo de resistência (André Ristum, 2004) e Vlado - 30 anos depois (João Batista de Andrade, 2006). O que distingue as duas obras é que numa a narrativa está voltada para o particular, enquanto que a outra, está centrada em narrar o geral. Mas, quando os testemunhos ocupam-se em narrar as torturas, as diferenças entre os filmes desaparecem. Assim, buscamos entender as razões que justificam a repetição do mesmo discurso, a tortura, nestes filmes, para em um segundo momento, compreendermos como os depoimentos sobre a tortura se estruturam, a partir da noção de "enquadramento" proposta por Michael Pollack. Com essa finalidade, buscamos analisar, auxiliados pelos estudos de Walter Benjamin, a relação destes depoimentos com uma peculiaridade que marca a sociedade contemporânea: a expropriação da experiência.
\end{abstract}

Palavras-chave: enquadramento. Experiência. Tortura. documentário brasileiro

\begin{abstract}
This present article analyzes two documentary films about the Brazilian military dictatorship: Tempo de Resistência (André Ristum, 2004) and Vlado- 30 anos depois (João Batista de Andrade, 2006). What distinguishes the two works is that in one the narrative is turned to the particular, while the other is centered to narrate the general. But when the testimonies busy themselves to narrate the tortures, the differences between the films disappear. So, we try to understand the reasons which justify the repetition of the same speech, the torture, in these films, in a second moment understand how the testimonies about the torture organize themselves, from the notion of "framing" proposed by Michael Pollack. With this finality, we try to analyze, assisted by the studies of Walter Benjamin, the relation of these testimonies with a particularity that shows the contemporary society: the expropriation of experience.
\end{abstract}

Key-words: framing. Experience. Torture. brazilian documentary

Tempo de resistência (André Ristum, 2004) é uma adaptação do livro, de mesmo nome, de Leopoldo Paulino, que narra a história política do Brasil de 1964 até a declaração da

\footnotetext{
${ }^{1}$ Este artigo foi desenvolvido dentro do projeto $A$ representação fílmica da ditadura militar no Brasil com apoio do CNPq e PBA-PUCRS.

${ }^{2}$ Professora do Programa de Pós-graduação da Faculdade de Comunicação da PUCRS e pesquisadora CNPq (cristianefreitas@pucrs.br). Coordena o projeto A representação filmica da ditadura militar no Brasil

${ }_{3}$ Doutoranda do Programa de Pós-graduação da Faculdade de Comunicação da PUCRS e bolsista do CNPQ (lenastigger@hotmail.com). Integrante do projeto A representação filmica da ditadura militar no Brasil.

${ }^{4}$ Bacharelando em jornalismo e bolsista PBA-PUCRS (lucarmonac@gmail.com). Integrante do projeto $A$ representação filmica da ditadura militar no Brasil.
} 
Lei 6.683, de 28 de agosto de 1979, conhecida como Lei da Anistia, anunciada pelo presidente João Baptista Figueiredo. Vlado - 30 anos depois (João Batista de Andrade, 2006) conta a história do jornalista Vladimir Herzog, que foi preso, torturado e morto no estabelecimento do DÓI-CODI, órgão repressivo da ditadura militar. No filme de Ristum, a história da ditadura é retratada pela formação dos grupos da esquerda armada, pela clandestinidade e pelo fim dos mesmos. O filme de Andrade foca a trajetória profissional do jornalista e de seus colegas da TV Cultura de São Paulo, que foram presos durante a ditadura. Ambas as produções são documentários construídos com base em depoimentos de pessoas que apoiaram a resistência ao regime militar, alternados com imagens de arquivo, ilustrando os acontecimentos da época.

Apesar de um e outro corresponderem ao mesmo momento histórico, os documentários se diferem pelo recorte da abordagem. Tempo de resistência abrange uma história mais ampla da ditadura militar; o narrador em off, presente em toda a película, bem como os cartões em preto trazendo textos ilustrativos, são recursos fílmicos utilizados, didaticamente, para mostrar ao espectador, de forma cronológica, os fatos políticos do Brasil de 1964 até 1979. Vlado - 30 anos depois situa sua história em um âmbito mais particular, revelado já nos primeiros minutos de filme, quando o diretor se apresenta como amigo do jornalista e dedica sua obra a ele. Enquanto os depoimentos de Tempo de resistência tematizam a tortura, em Vlado - 30 anos depois, os amigos descrevem os maus tratos sofridos nos porões do DÓI-CODI. A distância entre o geral e o particular, que marcava a diferença dessas obras converge para um ponto em comum: a tortura, pois como informa um dos cartões de Tempo de resistência, "a principal arma da repressão era a tortura, que alcança níveis extremos de brutalidade". Portanto, ao assistir aos dois documentários, compreendemos a história do jornalista Herzog, assassinado pelos militares e conhecemos, através dos depoimentos de Tempo de resistência, um pouco da história dos grupos de esquerda armados. Assim, as narrativas não se repetem; cada uma relata um acontecimento diferenciado do período militar. No entanto, quando os testemunhos se ocupam em narrar as torturas, parece-nos que assistimos a um único filme.

Assim, buscamos entender as razões que justificam a repetição do mesmo no testemunho sobre a tortura, nestas obras, que podemos definir como filmes-testemunhos e em tantas outras sobre a ditadura militar, como verificado na pesquisa "A representação fílmica da ditadura militar no Brasil". Em especial, temos como objetivo, analisar como os depoimentos sobre a tortura se estruturam a partir da noção de "enquadramento", proposta por Michael Pollack e as contradições que daí surgem para a construção de uma imagem 
produzida pela lembrança do testemunho. Com essa finalidade, buscamos compreender, auxiliados pelos estudos de Walter Benjamin, a relação destes testemunhos com uma peculiaridade que marca a sociedade contemporânea: a expropriação da experiência.

\section{O vazio da experiência - Walter Benjamin}

De acordo com Benjamin, o fim da experiência assinala o mundo moderno. A morte costuma ser um espetáculo público onipresente nas praças, nas ruas e nas casas e, devido a um crescente processo de higienização passou a ser temida e, consequentemente, excluída dos espaços comunitários. No entanto, a morte concedia ao moribundo uma autoridade, pois somente com sua proximidade, o homem era capaz de repassar sua vida em memória e, a partir dela, transformar sua própria experiência em sabedoria.

Segundo a teoria de Benjamin, é de se esperar, portanto, que, diante da exaustiva vida moderna permeada de rápidas transformações sociais, o homem privado da experiência procure um sentido para sua vida.

Pobreza e experiência: não se deve imaginar que os homens aspirem a novas experiências. Não, eles aspiram a libertar-se de toda experiência, aspiram um mundo em que possam ostentar tão pura e tão claramente sua pobreza externa e interna, que algo decente possa resultar disso. (BENJAMIN, 1987, p.118)

No texto O narrador - considerações sobre a obra de Nikolai Leskov (1987), Benjamin começa descrevendo a inaptidão que o homem moderno tem em narrar um fato, cristalizando, deste modo, o vigor persuasivo já articulado em dois textos anteriores: Experiência e pobreza e Crise do romance. No percurso desta elaboração, Benjamin retoma a constatação de que a experiência está em vias de desaparecer na sociedade contemporânea; no entanto, neste último texto, o autor defende seu ponto de vista de maneira mais ilustrada. Evidenciando a oralidade, entende-se que essas histórias não eram contadas sempre do mesmo modo, as narrativas se construíam e se reproduziam na voz de cada novo orador. Em especial, na oralidade do camponês que dispunha do tempo e do viajante, que retinha o espaço. Mas, pode-se intuir que o elemento primordial da narrativa era a sabedoria.

Por princípio, as narrativas são baseadas em descrições; o narrador não inaugura um sentido, mas apenas se atém em narrar as travessuras do herói. Por força desta tradição, a narrativa torna-se uma obra aberta para a interpretação de cada ouvinte e, à medida que ela se 
reproduz, soma-se uma nova camada. Conforme Benjamin, é na narrativa épica que culminam todas essas reproduções da experiência. No que concerne o romance, a sabedoria desaparece e sua origem remonta a Antiguidade, mas seu desenvolvimento pleno só foi possível com a evolução técnica da sociedade burguesa. Ele é compatível com o rápido desenvolvimento da técnica, as subsequentes transformações do mundo social e a perda da referência das gerações anteriores. Deste modo, o indivíduo, ao mesmo tempo em que é exposto a acontecimentos atrozes como a guerra, perde seu marco referencial da tradição na narrativa oral. Portanto, ciente da impossibilidade do acesso à experiência, esse indivíduo procura no romance um sentido para a sua vida.

O romancista se separou do povo e do que ele faz. A matriz do romance é o indivíduo em sua solidão. O homem que não pode mais falar exemplarmente sobre suas preocupações, a quem ninguém pode dar conselhos, e que não sabe dar conselhos a ninguém. (BENJAMIN, 1987, p.54)

O romance se caracteriza por um tipo de literatura escrita que incorpora a informação na sua estrutura. "Essa forma de lapidar mostra claramente que o saber que vem de longe encontra hoje menos ouvintes que a informação sobre acontecimentos próximos"(BENJAMIN, 1987, p.202). Neste contexto, é interessante apontar uma evidência que o autor verifica na passagem de substituição da narrativa épica para o romance, que decorre da informação. Pois, conforme o autor, o caráter da informação é sua "verificação imediata", ou seja, o romance, que tem a informação como sua característica principal, precisa dizer algo aos leitores que seja coerente com um lugar e um tempo específico. Por outro lado, a narrativa épica era construída a partir de histórias extraordinárias. Daí resulta sua sabedoria e sua atemporalidade. $\mathrm{O}$ romance é uma obra fechada, o autor dá o sentido para o texto. $\mathrm{O}$ leitor lê e retém essa acepção para a sua vida. Porém, no que se refere à obra épica:

Quanto maior a naturalidade com que o narrador renunciar às sutilezas psicológicas, mais facilmente a história se gravará na memória do ouvinte, mais completamente ela se assimilará à sua própria experiência e mais irresistivelmente ele cederá à inclinação de recontá-la um dia. Esse processo de assimilações se dá em camadas muito profundas e exige um estado de distensão que se torna cada vez mais raro. (BENJAMIN, 1987, p.204)

A análise até aqui esboçada, sustentada na teoria de Benjamin, assinala o fim da experiência perante a rápida mudança social, tecnológica e econômica do mundo ocidental após a Primeira Guerra Mundial. Em tal exame, não nos cabe determinar se a experiência, de 
fato, deixou de existir. O que nos é valioso, nesta reflexão, é que, a partir de Benjamin, podemos entender que a relação da experiência, assim como a percepção da arte, está pautada em uma nova configuração. Para o desenvolvimento desse raciocínio, reportamo-nos, novamente, aos estudos de Benjamin, a fim de evidenciar o modo como o cinema brasileiro está se estruturando para repassar a experiência histórica da ditadura militar.

\section{O cinema e a experiência}

No seu texto $A$ obra de arte na era de sua reprodutibilidade técnica, Benjamin atribui um papel primordial ao cinema. A reprodução deslocou esse objeto do seu suporte ritualístico, pautado numa tradição, e o desacralizou. Portanto, cessado um antigo modo ritualizado da arte, institui-se uma nova percepção da mesma. No centro de tal pensamento, o cinema tornase o representante dessas mudanças.

Benjamin apresenta dois personagens: o pintor e o cineasta. Na pintura, é necessária a longitude e a observação do objeto para a reprodução; somente após este exercício, o pintor pinta a realidade. No cinema, o princípio de sua linguagem está baseado na montagem de planos e na construção dos mesmos, através de escolhas técnicas tais como o posicionamento e ângulo da câmera, iluminação, etc. Logo, diferentemente do pintor, o cineasta não apenas observa a realidade mantendo uma distancia, mas a recria artificialmente.

Diante dessas teorias aqui expostas, que sustentam o fim da experiência e a transformação no modo como nos relacionamos com a arte, parece-nos evidente que a finalidade do cinema é buscar um meio de sobrevivência da obra aberta. Por força da construção técnica, um filme sugere novas perspectivas do cotidiano quando, por exemplo, propõe a transfiguração do movimento natural dos objetos, criando desse modo, nas palavras de Benjamin, "uma experiência do inconsciente óptico". Podemos, então, fazer um paralelo com as narrativas orais descritas pelo autor que, do mesmo modo que o cinema, caracterizamse pela abertura interpretativa do receptor. Valendo-se dessa análise entendemos que o modo de construção fílmica possibilita a permanência da memória da tortura nas gerações posteriores.

Aqui intervém a câmera com seus inúmeros recursos auxiliares, suas imersões e suas acelerações, suas ampliações e suas miniaturizações. Ela nos abre, pela primeira vez, a experiência do inconsciente ótico, do mesmo modo que a psicanálise nos abre a experiência do inconsciente pulsional. De resto, existem entre os dois inconscientes as relações estreitas. Pois os múltiplos aspectos que o aparelho pode registrar do aspecto sensível normal. (BENJAMIN, 1987, pp.189-190) 
Em conformidade com o pensamento de Benjamin, podemos entender que há hoje uma nova maneira de construção e reprodução das experiências, e essa mudança não implica, necessariamente, no caminho do seu aniquilamento. A ênfase, colocada pelo autor, de que a era da reprodutividade inaugurou uma nova percepção da arte e o cinema seria o seu maior exemplo, poderia também ser ampliada para a nova configuração da experiência. $\mathrm{O}$ emprego sistêmico da representação da tortura, nos filmes sobre a ditadura militar, em especial os aqui analisados, Tempo de resistência e Vlado - 30 anos depois, levam-nos a investigar que recursos o cinema está utilizando para manter a experiência histórica, a começar pelos aparatos técnicos que podem apresentar uma perspectiva do cotidiano, até então invisível ao olho nu.

Assim podemos exemplificar esse fenômeno da repetição através de testemunhos que se referem à temida cadeira do dragão, apresentada de maneira muito semelhante por Carlos Russo Jr. ${ }^{5}$ (Tempo de resistência) e Sérgio Gomes ${ }^{6}$ (Vlado), respectivamente.

Cadeira do Dragão é uma cadeira que você senta e ela é toda forrada com chapas metálicas, também chapas metálicas prendem tuas pernas, teus braços e a partir daí, com magneto, eles conectam aquilo ou ao teu escroto, ou a tua língua, ou a tua orelha, em dois pontos do corpo e inicia o processo de choque elétrico na cadeira do dragão", "[cadeira do dragão] era como se fosse um trono com tampo de metal, e se amarrava os braços e as pernas atrás de um sarrafo. Você ficava totalmente imobilizado. É a prática mais regular é de amarrar um fio na orelha e outro no pinto e aí com o dínamo dar choque.

Ainda que haja uma distinção entre uma história voltada para o particular, como no filme Vlado - 30 anos depois, e outra focada na história mais geral da ditadura militar, a exemplo de Tempo de resistência, parece-nos que estamos assistindo ao mesmo filme. Essa profunda conexão entre as obras se dá na repetição dos depoimentos sobre a tortura, pois se trata sempre do mesmo. A partir desta conduta uniforme, reportamo-nos ao estudo da diferença e da repetição de Gilles Deleuze para buscar compreender o propósito em que está fundada a repetição do mesmo nestes filmes, mas antes precisamos nos deter nos testemunhos.

\footnotetext{
${ }^{5}$ Militante Político de 1960/1970, pertencente ao PCB, posteriormente DI e ALN. Ex-vice presidente da UEE1968/1969. Preso político de abril de 1970 a março de 1974 e exilado político de 1974 a 1976.

${ }^{6}$ Jornalista, na época da Ditadura Militar teve ligação com o movimento estudantil da USP. Foi preso pela Operação Jacarta em outubro de 1975.
} 


\section{Do enquadramento à repetição}

Cabe observar, nesses testemunhos, que os presos políticos eram capturados sempre da mesma forma e torturados da mesma maneira; nesse sentido, as narrativas se repetem ${ }^{7}$. Conforme Deleuze, existe uma diferença entre generalidade e repetição. Na generalidade, um termo pode ser substituído pelo outro através da propriedade da semelhança, enquanto que, na repetição, a substituição é impossível, pois não existe um equivalente, ou seja, o diferente é único, e ele retorna para a repetição. "Opõe-se, pois, a generalidade como generalidade do particular, e a repetição como universalidade do singular" (DELEUZE, 2006, p.20). Quando um evento histórico, como a Lei da Anistia, ocorre, permitindo o regresso dos exilados políticos ao Brasil, não significa que todos os aniversários referentes ao fato o revivam, mas significa que esta lei antecipou todas as futuras comemorações, pois se trata de um tipo de evento, que, através dos estudos de Deleuze, pode-se compreender como algo impossível de recomeçar; trata-se de uma singularidade que se repete a cada data comemorativa. Assim, não existem equivalências ou substituições, ainda conforme o mesmo autor.

A diferença é percebida através da exterioridade e é no meio do habitual que ela se sobressai. O autor enfatiza que, neste mecanismo da diferença e da repetição, é essencial o esquecimento, pois através dele, o diferente pode repetir-se inúmeras vezes, e, como em uma primeira vez, será percebido pela exterioridade com espanto. Entre o objeto e o sujeito, existe uma operação cognitiva. Ao reconhecer um objeto, a representação dele trabalha na memória do sujeito. Quando não ocorre esse processo de reconhecimento, o objeto tende a se repetir para o sujeito. No entanto, se ele é reconhecido, a sua representação, na memória, transformase em conhecimento para o indivíduo. Deleuze lembra ainda que essa operação cognitiva foi amplamente estudada por Freud e, na psicanálise, a inexistência da recordação remete a um bloqueio ou recalque do sujeito. Assim, "repete-se tanto mais o passado quanto menos ele é recordado, quanto menos consciência se tem de recordá-lo, recorde, elabore a recordação para não repetir" (DELEUZE, 2006, p. 37).

Posto desta forma, é provável que os filmes aqui analisados busquem o sentido contrário da lei que rege a diferença e a repetição. Promover a memória da tortura impediria seu esquecimento, logo, sua repetição. O que se presume é que a vivência das pessoas deve ser repassada ao coletivo através da experiência.

\footnotetext{
${ }^{7}$ Mesmo que existam diferenças, nos testemunhos, referimo-nos a determindas invariantes dos mesmos na sequência seqüestro-tortura, entre outras.
} 
Assim, podemos destacar uma forma de agressão física que foi relatada em ambos os filmes e se refere a técnica denominada pelos torturadores como 'pimentinha', segundo Rodolfo Konder ${ }^{8}$, no documentário de Andrade.

A pimentinha era uma máquina de choques elétricos. Vieram dois sujeitos aos gritos, eu estava sentado em um banco, capuz preto na cabeça, aí instalaram a máquina e obrigaram eu mesmo a botar os fios nos pulsos e nos tornozelos e começaram a me dar choque elétricos. Inclusive um deles com um fio desencapado me dava choques no pescoço, na orelha, nas costas.

José Adolfo de Granville" o fez da seguinte forma: "Pau-de-arara" tem um fio em volta da grade, tem um fio nas orelhas e tem um outro fio que eles ficam passando em todo o lugar. E ele vira uma manivela na máquina que gera a energia que dá o choque". Cabe observar que os depoimentos trazem sempre o mesmo relato da experiência, mas isso não quer dizer que eles sejam semelhantes entre si e que correspondem a uma generalidade no sentido que nos foi dado por Deleuze. Mas, ao contrário, os depoimentos são únicos e sempre o mesmo e por serem assim, é que eles se repetem.

\section{Do enquadramento à tortura}

Para Michael Pollack (1989), a memória é estabelecida para delimitar as fronteiras e permitir a harmonia dentro de um determinado grupo social. Para isso é preciso "enquadrar"11 determinadas referências que são justificadas pelas ações humanas, embasadas pelo material oriundo da história. Esse material pode ser interpretado de várias maneiras com o objetivo de manter ou expandir as fronteiras de grupo e consiste em uma reinterpretação do passado, ou seja, manter uma imagem coerente com a sua história para dar credibilidade ao grupo. Em relação à Ditadura Militar no Brasil, podemos destacar o Grupo Tortura Nunca Mais, entidade

\footnotetext{
${ }^{8}$ Diretor do Sindicato dos Petroleiros do antigo Estado da Guanabara na época da implantação da ditadura militar de 1964-1985, e, acusado de militante do PCB, teve de se exilar. Estava preso no Dói-Codi quando Herzog foi assassinado, em 25 de outubro de 1975.

9 Jornalista preso em Ribeirão Preto, em 1964 por sua ligação com o PCB. É um dos autores do livro "Tiradentes, o Presídio da Ditadura", que relata a prisão de opositores ao governo autoritário da época.

${ }^{10}$ Segundo o depoimento do Augusto César Salles Galvão, na coletânea que integra o projeto Brasil Nunca Mais, pau de arara é definido como "uma barra de ferro atravessada entre os punhos amarrados e a dobra do joelho, sendo o "conjunto" colocado entre duas mesas, ficando o corpo do torturado pendurado acerca de $20 \mathrm{~cm}$ ou $30 \mathrm{~cm}$ do solo. Este método quase nunca é utilizado isoladamente, os seus "complementos" normais são eletrochoques, a palmatória e o afogamento"(1985, pp.34). Percebe-se a associação entre a descrição da "pimentinha" e do "pau-de-arara".

${ }^{11}$ Pollack parte do conceito de "memória coletiva", desenvolvido por Maurice Halbawachs (1997) para defender a idéia de enquadramento. Segundo Halbawachs, a memória é construída através de uma troca entre indivíduos e as suas transformações dependem do meio, onde essas relações se desenvolvem de forma coletiva.
} 
suprapartidária fundada em 1985 por ex-prisioneiros políticos que foram torturados e por familiares de militantes mortos ou desaparecidos durante o regime militar; diversas manifestações espalharam-se, em todo país, em função dos 30 anos do decreto que promulgava a Lei da Anistia, como dito anteriormente; a orientação iniciada em 2002 na gestão de Fernando Henrique Cardoso, mas que encontrou eco no atual governo federal em indenizar ex-presos e militantes políticos ou seus familiares ${ }^{12}$.

Existe, então, um trabalho de enquadramento da memória coletiva, realizado por atores sociais profissionais, que Pollack define como os "profissionais da história" (1989, pp.9). Tais profissionais, geralmente, ocupam-se de pesquisar os testemunhos e, assim, construir uma imagem dos fatos.

Essa imagem implica em uma relação entre o objetivo e o subjetivo, isto é, entre a reconstrução dos fatos e as reações dos sentimentos pessoais. Assim, os testemunhos apresentados nos filmes, em especial aqui analisados, precisam passar para o público uma autenticidade para alcançarem credibilidade. Podemos citar o relato de Frederico Pessoa ${ }^{13}$ no documentário dirigido por Andrade:

Tem momentos que o sofrimento das outras pessoas chega a ser mais forte que o teu próprio sofrimento. Então quando você vê um amigo, um companheiro sendo torturado na tua frente, no meu caso, a minha mulher, isso te marca para o resto da vida.

Fazem parte também do enquadramento "os discursos organizados em torno de acontecimentos e de grandes personagens" (POLLACK, 1989, pp.10); essa característica é explicita em Vlado, filme que relata, após a morte de Herzog, as manifestações que desencadearam a abertura política no país, assim como em outros filmes biográficos como Marighella, retrato falado de um guerrilheiro (Silvio Tendler, 2001) ou em filmes sobre grandes acontecimentos como Hércules 56 (Silvio Da-Rin, 2007).

Além disso, podemos acrescentar, como constituinte dessa memória, os cheiros, os barulhos, os gritos, como ressaltados no documentário de Ristum através do testemunho de Vanderley Caixe, ${ }^{14}$ descrevendo a tortura psicológica:

\footnotetext{
${ }^{12}$ Esse tipo de indenização ficou pejorativamente conhecida, devido a polêmicas provocadas pela mídia sobre a sua legitimidade, como "bolsa ditadura" em analogia ao programa do governo Lula, determinado de "bolsa família".

${ }^{13}$ Jornalista, colega de Vladimir Herzog no período da Ditadura. Pertenceu à tendência Unidade, que lideraria o DCE da USP em 1979. Foi preso em 1975.

${ }_{14}$ Atuante no movimento estudantil, militou no PCB desde a juventude. Ficou por dois anos no cárcere (19721974). Depois se formou em Direito e presta assessoria para presos políticos.
} 
Uma variedade de torturas, desde o que todo mundo conhece que era o pau-de-arara, choque elétrico, afogamento, até a tortura psicológica, que é a pior delas. Tortura psicológica é você ver alguém ser torturado na sua frente, você ouvir gritos.

Já no documentário de Andrade podemos perceber essa lembrança sensitiva no depoimento de George Duque Estrada"15: "A primeira coisa que você sofria era um estressamento pelo barulho. A todo momento tocava-se campainha, a todo momento batia-se porta, para não deixar você estabilizar."

Devido a essa capacidade do cinema, Pollack define o filme como o melhor suporte para a captação e armazenamento desses traços subjetivos para a formação da memória, daí o "seu papel crescente na formação e reorganização e, portanto, no enquadramento da memória" (1989, pp.10).

Nos filmes sobre a Ditadura Militar no Brasil, o "enquadramento" da memória sobre a tortura é explicitado quase sempre através da utilização de um mesmo recurso técnico, como aparece nos documentários aqui analisados. Apresenta-se um quadro fechado no rosto das personagens no momento em que relatam o seu testemunho, destacando as diferentes expressões do rosto, o que permite transparecer os sentimentos. O uso desta técnica acaba tendo função pedagógica, com o compartilhamento da dor, potencializando os relatos.

Mesmo que, nos dois documentários, apareçam recursos de estilo diferenciados, os planos dos testemunhos, no longa-metragem Tempo de Resistência, são frontais, fixos e com enquadramentos aproximativos, geralmente em plano próximo. Em Vlado, o movimento da câmera é mais sentido, pois, em algumas tomadas, Andrade usa o recurso da câmera na mão. O enquadramento também é mais livre, sendo mais lateral em algumas cenas e, em outras, aparece no quadro o diretor e um dos personagens-testemunhas, como se fosse uma entrevista. No entanto, quando o assunto trata da tortura sofrida na Ditadura, os dois documentários utilizam sempre o mesmo recurso.

Segundo Pollack, "o filme-testemunho" tornou-se um instrumento poderoso para os rearranjos sucessivos da memória coletiva" (1989, p. 10). Assim, todos os instrumentos que propiciam a formação de uma memória coletiva, como as instituições, os grupos, passando pelos filmes, apresentam semelhanças, mas também tensões entre eles. Como os grupos sociais e as instituições são frequentemente efêmeros, pois sustentam-se na política, a

\footnotetext{
${ }^{15}$ Jornalista preso em 1975 , ligado ao PCB.
} 
memória sobrevive nas referências culturais, literárias, cinematográficas e religiosas. Dessa maneira, o passado torna-se questionável e permite a ordem estabelecida.

Nesse sentido, a reconstrução do passado auxilia na construção do futuro, possibilitando novos desafios a essa ordem. O estudo dos materiais e dos sujeitos que estabelecem o enquadramento da memória permite-nos perceber como a memória coletiva é construída, desconstruída e reconstruída e, ao lado do testemunho, provoca uma tensão entre a imagem oficial e a lembrança pessoal, trazendo à tona muitas contradições.

\section{Algumas reflexões finais}

A tortura passa a ser sistemática no país a partir da instauração do Ato Institucional número cinco, em dezembro de 1968, quando é decretada a suspensão de várias garantias constitucionais à população brasileira. Os dois longas-metragens analisados, Tempo de resistência e Vlado - 30 anos depois, sustentam os seus discursos na tortura. Nos testemunhos, há a descrição de tais atrocidades e podemos constatar muitas semelhanças nos relatos de quem sofreu com a ditadura.

Assim, pode-se dizer que dos 21 anos de ditadura militar (1964-1985), grande parte de toda a mobilização da representação fílmica, referente ao período, concentrou-se em mostrar a tortura $^{16}$. Prosseguindo nesta via, buscamos pensar que ela constituiu-se de uma prática única, diferenciada, que se repetiu e se repete em cada filme. Portanto, não é por acaso que evidenciamos, neste modo de representação, a presença da experiência. Pensamos também que chegou o momento em que certos fatos históricos tornam-se únicos e, como elementos únicos, precisam se repetir. Mas a tortura humilha e degrada o ser humano e, em função disso, uma cinematografia brasileira colabora para ela não ser esquecida.

O cinema nasceu no contexto da era da reprodutividade. Ele não tem um suporte fixo e tradicionalmente ritualizado. Sua linguagem é baseada na reconstrução da realidade a partir da técnica, modelo diverso do pintor que apenas observava seu objeto sem interagir na própria essência da realidade. Dito de outra maneira, o cinema inaugura uma nova possibilidade de reconstrução artística do mundo. E, como tal, a tortura é enquadrada e constantemente repetida de modo que os testemunhos dialogam com e contradizem a história oficial de um dos períodos mais impiedosos da política brasileira. Nesse sentido, o cinema não só narra as experiências, mas propõe novas imagens para a memória coletiva.

\footnotetext{
${ }^{16}$ Essa informação procede dos dados coletados e analisados no projeto de pesquisa já citado.
} 


\section{Referências bibliográficas}

BEJAMIN, Walter. Obras escolhidas - magia e técnica, arte e politica. São Paulo: Brasiliense, 1987. DELEUZE, Gilles. Diferença e repetição. São Paulo: Graal, 2006.

ECO, Umberto. Obra aberta. São Bernardo do Campo: Perspectiva, 2001.

HALBWACHS, Maurice. La mémoire collective. Paris: Albin Michel, 1997.

POLLACK, Michael. Memória, Esquecimento, Silêncio. IN: Estudos Históricos, vol. 2, n.3. Rio de Janeiro. 1989.

\section{Filmes citados}

Marighella, retrato falado de um guerrilheiro (Silvio Tendler, 2001)

Tempo de resistência (André Ristum, 2004)

Vlado - 30 anos depois (João Batista Andrade, 2005)

Hércules 56 (Silvio Da-Rin, 2007) 